\title{
Synchronic resisto-genesis effects identify most prevalent mechanism in Acinetobacter baumannii
}

Najmeh Alaei, ${ }^{1 *}$ Abbas Bahador, ${ }^{2}$ Azadeh Alaei $^{3}$

${ }^{1}$ Young Researchers and Elite Club, Karaj Branch, Islamic Azad University, Karaj, Iran.

${ }^{2}$ Department of Microbiology, School of Medicine, Tehran University of Medical Sciences, Tehran, Iran.

${ }^{3}$ Young Researchers and Elite Club, Faculty of Advanced Science and Technology, Tehran Medical Science, Islamic Azad University, Tehran, Iran.

Corresponding authors:

Najmeh Alaei, Alaee.na@Gmail.com

Young Researchers and Elite Club, Karaj Branch, Islamic Azad University, Karaj, Iran

Young Researchers and Elite Club, Karaj Branch

Islamic Azad University, 31485 - 313, Moazen Blvd., Karaj, Iran

Tel: +98 $2634259571-9$

Fax: +982634418156

Abbas Bahador, abahador@sina.tums.ac.ir

Department of Microbiology, School of Medicine, Tehran University of Medical Sciences, Tehran, Iran

Department of Microbiology, School of Medicine

Tehran University of Medical Sciences, Keshavarz Blvd., 100 Poursina Ave., Tehran 1416753955, Iran

Tel: +98 2164053210

Fax: +98218895 5810

Co-author:

Azadeh Alaei, Alaee.a@Gmail.com

Young Researchers and Elite Club, Faculty of Advanced Science and Technology, Tehran Medical Science, Islamic Azad University, Tehran, Iran

Young Researchers and Elite Club, Faculty of Advanced Science and Technology Islamic Azad University of Medical Sciences, Khaghani St, Shariati Ave, Tehran 19395/1495, Iran Tehran, Iran 
bioRxiv preprint doi: https://doi.org/10.1101/2022.03.03.482757; this version posted March 3, 2022. The copyright holder for this preprint

\begin{abstract}
Acinetobacter baumannii as deadliest infection agent to ICU patients challenge experimental treatment in lack of new antibiotic and non-optimal recommendations. Despite confirm importance of infectious ICU sources, IC2 strains, ISAba/bla OXA genes and colistin in adequate concentrations or combination therapy due to potential heteroresistance; this study reveals unusual hypersensitive colistin- and sensitive aminoglycosides-resistant strains using designed methods, antibio-dendrogram classification and a computational table. Accordingly, lipopolysaccharide loss-mediated penetration and upregulated AdeAB pump-mediated compounds exclusion, are found to be causes of these abnormalities. Consequently, these simultaneous resistances termed synchronic resisto-genesis effects, drive population and create abnormal multidrug-resistant strains; while, delay extensively drug-resistant phenotype. This phenomenon predicts the predominant determinant mechanisms and makes abnormal behavior comprehensible among antibiotic-phenotypic levels or in vitro and vivo observations. Therefore, this method provides preclinical information to address therapeutic resistance in future microbial or cancer cell studies, and improves drug choosing in combination therapies, like use of inhibitory drugs.
\end{abstract}

\title{
Introduction
}

The multidrug-resistance progressed Acinetobacter baumannii $(A c B)$ in competition with Pseudomonas aeruginosa(Karageorgopoulos \& Falagas, 2008; Kim et al, 2009; Vincent et al, 2009) to cause the most threatening infections including ventilator-associated pneumonia (VAP),(Peleg \& Hooper, 2010; Wenzler et al, 2016) bacteremia,(Munoz-Price \& Weinstein, 2008; Tabah et al, 2012) and Gram negative-secondary meningitis(van de Beek et al, 2010) in the ICUs.(Munoz-Price \& Weinstein, 2008; Tabah et al., 2012)

Along with multidrug-resistant (MDR) infections, multiple-specificity of long-lasting survival on surfaces and global expansion highlighted molecular identification techniques of $A c B$ reservoirs for preventive monitoring.(Karageorgopoulos \& Falagas, 2008; Munoz-Price \& Weinstein, 2008) Accordingly, from late 1990s, the sophisticated amplified fragment length polymorphism (AFLP) classification as the most robust population structure mapping method depicts standardly distribution of predominant $A c B$ worldwide clonal lineages to discriminate genotypes to subspecies by whole genome analysis.(Janssen et al, 1996)

To date, various methods identifying clonal based on PCR and sequencing have been replaced the costly AFLP fingerprinting analysis, the most abundant of which are MLST, 3LST rep-PCR, and SBT. Although of these, the golden method, MLST in Pasteur scheme is expensive, trilocus sequence type (3LST) as a powerful screening criterion for large study populations distinguishes traditional international clones (ICs 1-3) without no sequencing by two selective multiplex PCR of three genes including endogenous bla $a_{\text {OXA-51-like }}$ gene evolving in AcB.(Zarrilli et al, 2013)

Resistance genes may also contribute to incidence, thereby over the last decade $A c B$ outbreaks surveillance has been accompanied by tracing particularly carbapenems-resistance genes, to the extent that the WHO has given priority to carbapenems-resistant $A c B(\mathrm{CR}-A c B)$ treatment research.(Tacconelli et al, 2018) To this end, in this study the dominant role of ISAba/bla $a_{\text {OXA }}$ genes in carbapenems-resistance were determined in contrast to other determinants comprising other $\beta$-lactamase enzymes, penicillin binding protein changes, permeability reduction and efflux pumps such as AdeABC.(Evans \& Amyes, 2014; Karageorgopoulos \& Falagas, 2008; Peleg \& Hooper, 2010; Woodford et al, 2006)

The most common genes extended spectrum $\beta$-lactamases, bla $a_{\mathrm{OXA}}$ encoding oxacillinase (OXA), have been already identified to 12 distinct groups based on amino acid sequences 
bioRxiv preprint doi: https//doi.org/10.1101/2022.03.03.482757; this version posted March 3, 2022. The copyright holder for this preprint

similarity, five of which are the main plasmid-borne groups in $A c B$ carbapenems-resistance, apart from endogenous $b l a_{\text {OXA-51-like }}$ genes. The smallest genetic stimulus elements, insertion sequences (ISs) upstream of blax genes upregulate oxacillinases genes. Moreover, ISs randomly transferred additional genes such as resistance genes between bacteria by constructing composite transposons.(Evans \& Amyes, 2014)

Based on these understandings, recent retrospective study with intervention approach to control the critical abundant infections with risk factors (ICU, MDR and CR$A c B$ ),(Karageorgopoulos \& Falagas, 2008; Munoz-Price \& Weinstein, 2008; Vincent et al., 2009) evaluate infection dispersion, resistance trends and the highly related carbapenemsresistance genes in $100 A c B$ MDR isolates. Therefore, the new study methods were conducted here with the aim of finding infection sources and drug selection for the treatment of severe $A c B$ infections in ICU patients; however, abnormal data showed more valuable results from simultaneous resistance.

\section{Results and Discussion}

\section{Characterization of $A c B$ Isolates of Nosocomial Infections}

$A c B$ in the epidemiological studies and antibiotics assays has gained recent attention due to eradication failure along with prolonged hospitalization in the ICU,(Munoz-Price \& Weinstein, 2008; Tabah et al., 2012), creating unique multidrug-resistance, especially to carbapenems and causing the most critical nosocomial infections of VAP,(Peleg \& Hooper, 2010; Wenzler et al., 2016) bacteremia,(Munoz-Price \& Weinstein, 2008; Tabah et al., 2012) Gram-negative meningitis.(van de Beek et al., 2010)

After resistant outbreaks observation in our previous findings from the ICUs at a referral hospital of Shiraz university,(Alaei et al, 2016) 100 non-repetitive MDR clinical $A c B$ isolates were investigated that achieved from hospitalized subjects (mean age: 39 years; 7 days to 93 years; 55(\%) female, 45(\%) male) and both seven specimens and locations. Predominantly samples were compiled from urinary $(41 \%)$ and respiratory $(30 \%)$ tracts; as well as internal (32\%) and surgical (27\%) ICUs (Figures 2D and 2G).

\section{Antibio-dendrogram and phenotypic classification}

First time in our previous study, the classification method termed antibio-dendrogram in this study, was created based on antimicrobial susceptibility patterns to provide inductive method for comparing resistance information with other datasets such as genetic data.(Alaei et al., 2016) Considering to former role of imipenem as a broad-spectrum agent for treating $A c B$ infections in ICU and the resistance increment among $A c B$ s to carbapenems as the first-line therapy against Gram-negative, the evaluation of antimicrobial efficacy among the CR-AcB strain has gained attention.(Humphreys et al, 1995; Kim et al., 2009; Munoz-Price \& Weinstein, 2008; Papp-Wallace et al, 2011) Therefore, antibio-dendrogram by double insertion of imipenem-resistance data introduced phenotypes that could be arranged in favour of a particular antibiotic (imipenem). Additionally, due to obtain an ambiguous and less efficient antibio-dendrogram for antibiotic-resistance diversity and rare similar antibiotic profiles, intermediate and resistant interpretive results were assumed equal (results not shown).

As a result, antibiotic profiles of 100 studied $A c B s$ by antibio-dendrogram were divided into 16 distinct antibiotypes (Figure 1A). All the $A c B$ isolates were completely resistant to cefotaxime, cefotaxime-clavulanate, kanamycin and amoxicillin-clavulanate; and contained resistance to at least one agent of antibiotic classes of $\beta$-lactam, $\beta$ - lactamase inhibitors and third-generation cephalosporins as less effective antibiotics (83-100\%); likewise, tigecycline, 
bioRxiv preprint doi: https://doi.org/10.1101/2022.03.03.482757; this version posted March 3, 2022. The copyright holder for this preprint

colistin, and tetracyclines as the most effective agents displayed the highest antibiotic sensitivity.

Once antibio-dendrogram is designed as the hierarchical clustering method based on frequency, represents the tree structure, such as 1,2 and 5 antibiotypes. Nevertheless, this arrangement did not exist in some others or in several more sensitive antibiotypes colistin as the most effective drug was found unexpectedly (7-9 and 16 biotypes), as well as tobramycin and netilmicin (with the 52\%, 65\% effects) in 9-11 and 14 antibiotypes.

Moreover, to obtain the resistance levels three antimicrobial classifications of multi-, extensively-, and pandrug-resistant (MDR, XDR, and PDR), was defined similar to that proposed by Magiorakos et al.,(Magiorakos et al, 2012) which XDR strains were considered sensitive to be at least three classes of all nine classes, thus isolates were assigned to $49(\%)$ MDR, 49(\%) XDR and two (\%) PDR strains.

\section{Observing Unusual Results}

Thereafter, antimicrobial resistance trends were evaluated to gain access to the best treatment option at each antibiotic phenotype. Unexpectedly, computational table (Table S1) and comparing resistance trend (Figure 1B) evidenced, although XDR strains are more resistant to MDR ones, resistances to colistin and aminoglycosides (tobramycin and netilmicin) were diminished in XDR and heightened in MDR strains relative to total. Comparative analysis of resistance trends in unexpected cases illustrated that resistance percentages to all antibiotics unusually reduced except minocycline, doxycycline and tigecycline $(26 \%, 20 \%$ and $2 \%$, respectively) at colistin resistant (CST-R) strains as well as to most antibiotics in aminoglycoside resistant (AGs-R) strains relative to total (Figures 1C and 1D).

To determine magnitude of resistance reduction in CST-R strains, total cases without reaching statistical significance in comparison with CST-R strains by more difference than that with MDR strains, was considered the best lower criterion (Figures $1 \mathrm{E}$ and $1 \mathrm{~F}$ ). In this way, for abnormal CST-R (CST-R $\left.{ }^{\mathrm{ab}}\right) A c B$, the comparison with the total strains confirmed a significant decrement versus insignificant increment of resistances (Figure $1 \mathrm{G}$ ). On the other hand, MDR strains by more difference to AGs-R strains than total was selected to explore the etiology of unexpected changes in the AGs-R strains as the lower criterion (Figures $1 \mathrm{E}$ and $1 \mathrm{~F})$, that significant increment of antimicrobial resistances was found in AGs-R strains compared to MDR strains (Figure 1H). Nevertheless, the existence of two different resistance patterns for AGs-R strains, including either sum or subscription of tobramycin and netilmicinresistance make its interpretation confusing. For this purpose, owing to moderate aminoglycosides-resistance among studied abnormal AGs-R (AGs-R ${ }^{\mathrm{ab}}$ ) strains, the sum of the aminoglycoside resistances indicating weak mechanisms was taken as the target antibiogram. Therefore, the antibiogram consisting of 61 tobramycin- or netilmicin-resistant cases was assumed for this phenotype that demonstrate dramatic resistance increase to all antibiotics except colistin and cephalosporins (Table S1). Crucially, abnormal resistance decrease of some agents in AGs-R strains can be due to decreased resistance of the same antibiotics or increased resistance of the opposite group. To identify abnormalities, in consistent with aminoglycosides change determined in prior computational step unexpected (Figures 1B-1D), the resistance increments were accounted abnormal.

\section{Explanation of Relationships in Genotypic Diversities and Carbapenems Resistance Genes}

From the aspect of genetics, with prevent approach of $A c B$ infections spread, two assays by different purposes were used here.

The 3LEST method to compare epidemiological genetic diversities of $A c B s$ in the worldwide spatial and temporal scales, without sequencing good designed for a large scale, and cost- effectively than the PFGE and MLST identify three current main global outbreaks 
bioRxiv preprint doi: https://doi.org/10.1101/2022.03.03.482757; this version posted March 3,2022 . The copyright holder for this preprint (which was not certified by peer review) is the author/funder, who has granted bioRxiv a license to display the preprint in perpetuity. It is made available under aCC-BY 4.0 International license.

of sequence groups (SGs) 1-3, representing international clones (ICs) II, I and III, respectively.(Hamouda et al, 2010; Zarrilli et al., 2013) The majority of isolates (75\%) were allocated to IC2/SG1 likewise $18(\%)$ isolates to IC1/SG2, while no isolate was belonging to SG3/IC3 in our study. Others (seven isolates) without overlapping with any previous putative genotypes, were considered novel variant of SGs (SGv).

Alternatively, AFLP genotyping with high verifiability and acceptable reproducibility, closely differentiate $A c B$ to intraspecific levels by the whole genome analysis relative to MLST and the amplified fragments relative to PFGE.(Hamouda et al., 2010; Turton et al, 2007; Zarrilli et al., 2013) Also, AFLP as a population structure study tool were modified in this study to enhance resolution. Constructed dendrogram by BioNumerics program based on 3LEST data, displayed 25 genotypes with two cut-off levels, in which eight major genotypes (1A-C, 5-7, 10 and 18) identified as the most common clinical outbreaks in this study (Figure 2A).

In terms of treatment options, resistance acquisition by either horizontal transfer or upregulation of genes through mutations or ISs induction make $A c B$ challenging. Up to now, following increase usage of imipenem against klebsiella and environmental durability of $A c B$, $b a_{\text {OXA }}$ genes as the most significant determinants involved in clinical CR-AcB,(Evans \& Amyes, 2014; Karageorgopoulos \& Falagas, 2008; Woodford et al., 2006) have been evolved under selective pressure into the five main oxacillinases groups $b l a_{\text {OXA-23-like, }}, b l a_{\text {OXA-24/40-like, }}$, $b l a_{\text {OXA-51-like, }}, b l a_{\text {OXA-58-like }}$ and $b l a_{\text {OXA-143-like, }}$ that their detection would demonstrate horizontal transfer and predominant protected contribution rather than other involved determinants. Notably, the chromosome-encoded OXA-51 weak carbapenemase and OXA-23, the most extensive acquired intermediate $\beta$-lactamases in $A c B$ species, mostly upregulated with ISAbal and ISA $b a 4$ elements and created a potentially serious problem with high resistance-

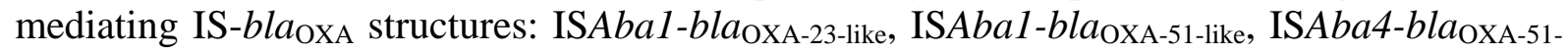
like. Apart from overexpressing downstream genes, the IS elements with high prevalence could cause horizontal bla $a_{\mathrm{OXA}} \mathrm{S}$ transfer between inter- or extra-species in colonized environments through genes-bracketing composite transposons.(Evans \& Amyes, 2014; Higgins et al, 2010a)

Our observation demonstrated that among ISA $b a / b l a_{\mathrm{OXA}}$, all studied $A c B$ were positive for intrinsic $b l a_{\text {OXA-51-like }}$ and the bla $a_{\text {OXA-23-like }}$ in the $49(\%)$ isolates routinely acquired in both carbapenems-susceptible and CR-AcB, similar bla $a_{\text {OXA-40/24-like }}$ in the $15(\%)$ isolates. Whereas from all studied $b l a_{\mathrm{OXA}} \mathrm{s}$, bla $a_{\mathrm{OXA}-58-\text { like }}$ gene in only five $(\%) \mathrm{CR}-A c B$ isolates was found in unique little association with both imipenem and meropenem resistance. Moreover, The PCR data were negative for $b l a_{\text {OXA-143-like gene in overall. ISAbal upstream of } b l a_{\text {OXA-51-like }} \text { gene }}$ (32\%) was the most widespread studied ISAbalbla $a_{\text {OXA }}$ genes than ISAbal and ISAba4 upstream of bla OXA-23-like gene in $14(\%)$ and $8(\%) A c B$ isolates, respectively. Comparison of mentioned genes revealed more associations between carbapenems-resistance and all three IS genes, then imipenem-resistance was affected by ISAbalbla $a_{\mathrm{OXA}}$ genes. Only, the ISAbal-

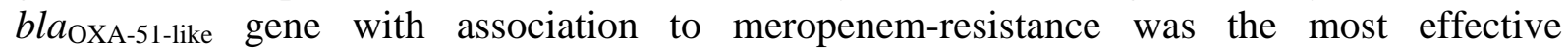
determinant at carbapenems-resistance (Figure 2B). Furthermore, although relative frequency distribution of $b l a_{\mathrm{OXA}}$ and ISAba genes pointed roughly equal percentages in both IC1/SG2

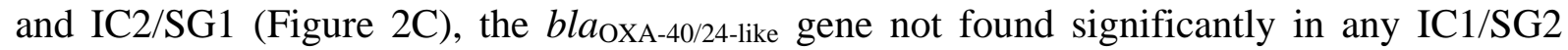
isolates $(P=<0 / 0001)$.

\section{Observing Concurrency in Resistances and Etiology}

Initially, colistin and aminoglycosides were thought that synergistically alter other antibiotic activities. Interestingly, published data implied that polycationic antibiotics including colistin and aminoglycosides, disrupt the outer-membrane stability through breaking down crossbridging in competition with LPS-binding cation ions, leading to self-uptake pathway and enhanced permeability to hydrophobic-antibiotics.(Hancock, 1984; Vaara, 1992) Therefore, 
bioRxiv preprint doi: https://doi.org/10.1101/2022.03.03.482757; this version posted March 3, 2022. The copyright holder for this preprint

colistin and aminoglycosides as outer-membrane permeabilizers increased susceptibility to hydrophobic antibiotics. Nonetheless, in this study, only each Etest represents interest antibiotic effect on untreated $A c B$ cells to simulate a monotherapy method.

We hypothesized that this is due to the fact that the simultaneous multi-resistance alterations conduct abnormalities in level before drug interactions, to this end similar phenotypes were followed up in the resistance mechanisms to colistin and aminoglycosides. Two main putative mechanisms modifying LPS as target site confer colistin-resistance in $A c B$ : Mutation deleting LPS within the basic structural genes $\operatorname{lp} x A, C, D$;(Moffatt et al, 2010) and alternatively, constitutive mutation of $p m r A, B$ genes overexpressing downstream target genes adding phosphoethanolamine (Figure 3).(Adams et al, 2009) Notably, resistance to cationic antimicrobial peptides in some Gram-negative Enterobacteriaceae, is produced by two-component system (TCS) including $p h o P Q$ genes upregulated $p m r A B$ genes, in which OprH protein can help with the oprHPQ operon cotranscription.(Macfarlane et al, 2000; Olaitan et al, 2014) Nevertheless, evolutionary elimination of PmrAB/PhoPQ cooperation is suggested in $A c B$;(Olaitan et al., 2014) and contrary to our findings, the PmrAB TCS induce concurrent colistin and aminoglycosides-resistance. Consequently, suggested phenotypes for AGs- $\mathrm{R}^{\mathrm{ab}}$ and CST- $\mathrm{R}^{\mathrm{ab}}$ strains were not in line with resultant phenotypes of simultaneous colistin- and aminoglycosides-resistance, such as synergistic effects, membrane-permeabilizer peptides, TCS activity of PmrAB or PhoPQ, and OprH protein.

The first similar observations to this sensitive CST- $\mathrm{R}^{\mathrm{ab}}$ strains by Li et al. was reported with lowered fitness and virulence(Li et al, 2007) which justifies the inability to expand these strains in Figure 2A. Subsequently, Fernández-Reyes et al. using expression assay of similar CST-R $^{\mathrm{ab}}$ strains demonstrated the regulation changes of 35 proteins associated with high antibiotic susceptibility,(Fernández-Reyes et al, 2009) that did not consistent with the wide range of unusual changes in our study. Eventually, Moffatt et al. attributed this atypical permeation to lpx genes inactivation causing LPS loss in outer-membrane.(Moffatt et al., 2010) Also, numerous articles have recently confirmed substantial widely sensitivity and virulence reduction in CST-R AcBs(Beceiro et al, 2014; Durante-Mangoni et al, 2015; Pournaras et al, 2014) and more colistin efficacy in combination therapy against $A c B$ compared to other Gram-negatives.(Vidaillac et al, 2012; Yahav et al, 2012)

According to this perspective, the survey of molecular parameters involved in penetration (configuration, size and distribution coefficient) showed that the complex permeability process is debatable, when the compounds have little structural difference like an antibiotic class. Thus, LPS loss-mediated colistin-resistance in $A c B$ more affected on most lipophilic and hydrophilic compounds in the same antibiotic classes (Table S1). Additionally, comparing piperacillin with piperacillin-tazobactam in Table S1 referred to impressive effect of $\beta$-lactamase inhibitor when periplasmic hydrolysing enzymes are reduced upon release from defective outer-membrane.

It should be noted that despite growing evidence for CST- $\mathrm{R}^{\mathrm{ab}}$ strain phenotype, the reason of tetracyclines and tigecycline-resistance increments in contrast to other antibiotics is unclear. In this respect, comparisons of estimated alterations among minocycline, doxycycline and tigecycline substantiated that hydrophobicity parameters not participate in this discrepancy because of equal $\log P$ values $(\sim-3 \cdot 5)$, the incompatibility between molecular weights and the resistance increment magnitude as well as between differences of changes among resistances and $\log D$ s in three agents (Table S2). Then current study for the first time suggests that in sensitive CST-R ${ }^{\mathrm{ab}}$ strains, mitigate integrity of cell-wall leads to low intracellular concentration and increased resistance to tetracyclines and tigecycline unlike others, due to high permeability of defective outer-membrane and concentration dependent activity in these three antibiotics. Therefore, in competition with amino acid carriers, 
bioRxiv preprint doi: https://doi.org/10.1101/2022.03.03.482757; this version posted March 3, 2022. The copyright holder for this preprint

tigecycline with higher affinity to ribosomes(Jenner et al, 2013) was less affected than other tetracyclines (Tables S1 and S2; Figures 1C, 1D and 1G).

Among the three mechanisms of aminoglycoside-resistance, the involvements of aminoglycoside-modifying enzymes with limited substrates and mutation with need to multiple binding sites of ribosome except streptomycin with a single binding site, were impossible.(Magalhães \& Blanchard, 2009; Magnet \& Blanchard, 2005) Eventually, developing resistance to the wide antimicrobial range specially aminoglycosides by AdeABC efflux pump with most similarity to our results was suggested as a causative factor.(Coyne et al, 2011; Yoon et al, 2015; Yoon et al, 2013) Efflux pumps mediating low-resistance along with severe outer-membrane barrier provide moderate-resistance at MDR AcBs, $(\mathrm{Li}$ et al, 2015) that with participation of other intermediate resistant mechanisms form current dissimilar AGs-R ${ }^{\mathrm{ab}}$ antibiograms.(Yoon et al., 2015) Resistance nodulation division (RND) pump shown in Figure 3 as most extensive one of the five putative super-families, compose of three components: outer membrane factor $(\mathrm{OMF})$, periplasmic membrane fusion protein (MFP), and RND transporter.(Coyne et al., 2011) Main intrinsic RNDs in $A c B$ comprising AdeABC, AdeFGH and AdeIJK efflux pumps regulate by upstream local adeRS and adeL genes in the opposite transcriptional orientation and $a d e N$ repressor at $800 \mathrm{kbp}$ of regulons, respectively. Overexpressing of these operons resulting from mutation in regulatory genes or the upstream ISs elements entrance, create acquired resistances by AdeABC, AdeFGH genes and intrinsic resistance by constructive expression of the adeIJK gene.(Li et al., 2015; Yoon et al., 2013)

In this context, literatures previously reported conflicting profiles of RND substrates. In latter study, Yoon et al. with superiority in using spontaneous mutants in regulatory genes or deletion of structural pump genes in non-MDR parents, precisely indicated reducing virulence and increasing resistances related to AdeABC, in which the collaboration between AdeIJK and $\mathrm{Ade} A B C$ was in the best agreement with our findings.(Yoon et al., 2015) Otherwise, our observations would not be consistent without the simultaneous intrinsic resistance of AdeIJK and the acquired resistance of Ade $\mathrm{ABC}$ to minocycline, $\beta$-lactams, and trimethoprim(Yoon et al., 2015) that firstly reported by Damier-Piolle et al. with sensitivity reduction to chloramphenicol, tetracyclines, tigecycline, macrolides, and fluoroquinolones.(Damier-Piolle et al, 2008) Noteworthy, except mutations or insertion of ISs in adeRS, both shuttle plasmid pCM88(Yoon et al., 2015) and BaeSR TCS(Lin et al, 2014) can make such situation.

In accordance with the AdeABC findings, outstanding resistance increment in AGs- $\mathrm{R}^{\mathrm{ab}}$ than MDR strains in Table S1 and Figures 1C, 1D and 1H, determined cationic compounds (aminoglycosides, ciprofloxacin),(Su et al, 2019) sulbactam and then carbapenems(Yoon et al., 2015) as the preferred agents of the AdeABC pump. The RND-type multidrug transporters located at inner membrane by multiple junction sits based on molecular size and charges with regardless of $\mathrm{PKa}$, captured broad-spectrum unrelated substrates from periplasm,(Colclough et al, 2020; Su et al., 2019) exception colistin, that not available in three RND due to either weight or its target in cell wall. Otherwise, like the specific channels such as TetA, they could have limited substrates.

Importantly, despite the over-resistance of abnormalities indicating AdeABC involvement, distinguish of these AGs- $\mathrm{R}^{\mathrm{ab}}$ strains from normal ones was challenging. In such a case, Nemec et al. suggested that netilmicin as a priority for this pump and for the less likelihood of involving another mechanism, can represent overexpressing adeABC gene at hyper-resistant AGs-R ${ }^{\mathrm{ab}}$ strains,(Nemec et al, 2007) denoted in Figure 2A. Furthermore, in prior study of CR$A c B$ strains upregulating $A d e A B C$, predominant contribution of pump than enzymatic mechanisms were inferred,(Yoon et al., 2015) that in comparison of 18 abnormal resistant $A c B s$ resistant to netilmicin and carbapenems with other CR-AcB strains (Figure 2B), the 
bioRxiv preprint doi: https://doi.org/10.1101/2022.03.03.482757; this version posted March 3, 2022. The copyright holder for this preprint

significant relationship reduction in between ISAba/bla $a_{\text {OXA }}$ genes and carbapenems-resistance was in line with this results.

Consequently, this study demonstrates that LPS-loss converts XDR to MDR strains, when causes hypersensitive CST-R $A c B$ or unusually MDR CST-R phenotype. While upregulated AdeABC delays promoting to the XDR phenotype in the lack of other mechanisms by reducing horizontal gene transfer and defecting biofilm formation, despite appearing MDR AGs-R strains.(Colclough et al., 2020) Ultimately, observed concurrent multi-resistance changes, termed the synchronic resisto-genesis effects phenomenon, occurs before drug interaction by nonspecific mechanism (permeability or efflux) that already confused with drug synergy. In fact, this computational table evident the differences of antibiogram and treatment strategies between different resistance levels (XDR and MDR) and in overall, or forecast shared multi-resistance mechanisms like ade $\mathrm{ABC}$ to determine appropriate combination therapy.

\section{Choosing Appropriate Treatment and Using Synchronic Resisto-Genesis Effects Phenomenon in Treatment of Resistant Diseases}

Reviving old drugs by improved formulation alike tigecycline and colistin, and optimizing combination therapy like synergistically sulbactam employment, have been suggested, although administration recommendations against MDR $A c B$ strains (AcBs) are still controversial.(Karageorgopoulos \& Falagas, 2008; Munoz-Price \& Weinstein, 2008; Penwell et al, 2015)

The suitable agents here were generally colistin, tigecycline, tetracyclines and aminoglycosides, while high sensitivity to imipenem, levofloxacin and sulbactam in MDR, CST-R and AGs-R AcBs were remarkable (Figure 1D). These relationships are also inversely found in reverse as shown in Table S1, thus colistin is the best treatment in all resistant groups except MDR strains, while synchronicity with aminoglycosides resistance is negligible. It should be noted that for local experimental therapy based on treatment strategies, in referral hospital the XDR strains is more expected; contrarily, in small hospitals by less-resistance the MDR strategy is suggested. Similarly, Table S1 attested that resistant strains to both carbapenems were highly resistant to sulbactam, also all imipenem-resistant $A c B s$ were sensitive to meropenem and sulbactam, and tigecycline co-occurred by doxycyclineresistance. Therefore, this phenomenon without any complex molecular technique disclosed the resistances concurrent and shared mechanism between carbapenems and sulbactam, or between doxycycline and tigecycline as well as unique mechanism of imipenem, which had been unknown in the past reports. In this way, in addition to discuss in stable resistance detectable at Etests,(Adams et al., 2009; Olaitan et al., 2014) the new method could recommend appropriate drug in confronting with specific resistance.

Crucially, apart from $l p x$ mutants found in this study, PmrAB in $90 \% A c B$ strains exposed to colistin reversibly confers heteroresistance.(Lim et al, 2010) Nonetheless, this study recommends colistin as best choice for $A c B s$ treatment in adequate doses or combination therapy such as co-administering with drug inhibitors of efflux pump or TCS PmrAB to prevent risk of resistance evolution under antibiotic selective pressure.(De Silva \& Kumar, 2019; Li et al., 2015) Notably, TCSs adapt Gram-negatives in response to environmental stimuli and broadly contribute to survival and virulence as shown in here for $A c B$. In this respect, dominant TCSs in the current study vary organism behaviour in vitro and vivo, since either AdeRS regulating adeABC or PmrAB in divalent cations, acidic $\mathrm{pH}$ and $\mathrm{Fe} 3+$ concentrations, by LPS modifications induce resistance to aminoglycosides and colistin (cationic peptides), respectively.(Mitrophanov et al, 2008; Winfield \& Groisman, 2004)

\section{Resistance factors and cross transmission implicated in distribution}


bioRxiv preprint doi: https://doi.org/10.1101/2022.03.03.482757; this version posted March 3, 2022. The copyright holder for this preprint

Epidemiological AFLP investigation detailed retrospectively clonal evolution and spatial or infectious distribution to implement appropriate interventional controls. Tracking 100 MDR outbreaks $A c B$ s from university hospital revealed main outbreak sources of respiratory and urinary tracts in accordance with prior publications(Fournier et al, 2006; Peleg \& Hooper, 2010) and internal and surgery wards that in Figure 2A, effective control of critical $A c B$ infections, especially PDR strains is good visible. Furthermore, the adaptability attributed to the most prevalent IC2 global clone(Zarrilli et al., 2013) with superiority in acquired resistance genes containing all ISAba/bla ${ }_{\mathrm{OXA}}$ genes was referable here in its prominent presence among AGs- $\mathrm{R}^{\mathrm{ab}}$ strains $(80 \%)$, which facilitated transfer in the main outbreak sources. Comparison of genotypic and phenotypic diversions in studied $A c B$ showed similar percentage distribution of different specimens and locations (Figures 2D, 2E, 2G and 2H), so that dispersion of dominant clone IC1/SG2 was in good agreement with total. Only presence of IC1 in urine and sputum samples and in parallel at the internal ICU without resistance superiority in IC genotypes highlight cross transmission in referral hospital of Shiraz with environmental pollution in IC1 (Figures $2 \mathrm{E}$ and $2 \mathrm{H}$ ). Nevertheless, these prominent presences of different clonal lineages (Figures 2D, 2F, 2G and 2I) were not significant, except IC1/SG2 that tended to dispense in internal ICU (Figure 2J).

As mentioned above, the expansion of AFLP clusters 1C, 10 and 7 indicated implications of XDR/PDR phenotypes and ISAba/bla $a_{\mathrm{OXA}}$ genes-containing strains, respectively; and pointed to resistance effect on cause of dangerous outbreaks (Figures 2A). However, the predominant existence of XDR and PDR strains representing highest resistance levels in urinary infections and central ICU in Namazi hospital, no significant difference in the presence or absence of XDR and PDR $A c B$ was detected (Figure 2J). In addition, the presence of acquired ISAbalbla $a_{\text {OXA }}$ genes in all AFLP clusters emphasised on horizontal transfer and evolution of these genes in selective pressure likewise, various clusters and seven singletons belonging most prevalent global clone of IC2/SG1 on ongoing expansion and genetic diversity.(Zarrilli et al., 2013).

In contrast, no prevalence of resistant cases (urine samples and central ICU as shown in Figures $2 \mathrm{~F}$ and 2I), phenotypic dissimilarity in AFLP genotypes even among 98\% similar strains and existing repeated cases among ICUs and specimens (bolded in Figure 2A), evidenced role of environmental then staff pollution before acquired resistance like gene transfer in prevalence.

Moreover, in current large-scale AFLP-dendrogram, denoted abnormalities indicate CST$\mathrm{R}^{\mathrm{ab}}$ strains presence in upper AFLP clusters in contrast to the throughout distribution of AGs$\mathrm{R}^{\mathrm{ab}}$ strains that represent role of mutations depending proliferation in CST- $\mathrm{R}^{\mathrm{ab}}$ strains and of random ISs insertion more than mutations in AGs- $\mathrm{R}^{\mathrm{ab}}$ strains.

\section{Conclusion}

In conclusion, this investigation noted treatment need for the threatening MDR outbreaks by the factors of $A c B$ distribution encompassing compatibility under selective pressure, environmental contamination and antimicrobial resistance, respectively. This report for the first time by terming the synchronic resisto-genesis effects phenomenon, revealed population drivers in the new mathematical method displaying unusual changes and could predict concurrent antibiotic-resistance and same unknown resistance mechanisms to apply in combination therapy also at other organisms or cancer cells for future. Therefore, this phenomenon by investigation in preclinical data of microorganisms expands the informative pharmacokinetic sources and approves use of inhibitory drugs to counteract the predominant determining mechanisms in the absence of new drugs. 
bioRxiv preprint doi: https://doi.org/10.1101/2022.03.03.482757; this version posted March 3, 2022. The copyright holder for this preprint (which was not certified by peer review) is the author/funder, who has granted bioRxiv a license to display the preprint in perpetuity. It is made available under aCC-BY 4.0 International license. 
bioRxiv preprint doi: https//doi.org/10.1101/2022.03.03.482757 this version posted March 3. 2022. The copvriaht holder for this preprint

\section{Materials and Methods}

\section{Isolates}

This retrospective study was commenced following the significant resistance observations at our previous study in 2017.(Alaei et al., 2016) Only compiled MDR AcB from different ICU wards of Namazi Hospital Shiraz Iran (Figure 1) were identified to species level using API20NE system (bioMérieux, Marcy-l'Etoile, France), later confirmed by gyrB-multiplex PCR in genomics species with interpreting of Higgins et al.(Higgins et al, 2010b)

\section{Antimicrobial assays}

In accordance with CLSI guideline,(Patel, 2017) disk diffusion method to assay all twenty antibiotic susceptibilities listed in Figure 2 (from Mast Diagnostics Ltd, Bootle, UK) and broth microdilution MIC of colistin and imipenem (assessing role of oxacillinase in carbapenems-resistance) were performed, except for tigecycline that EUCAST proposed breakpoints for Enterobacteriaceae were scored.(Testing \& Testing, 2019) Ensuring accuracy of each test was assayed by Escherichia coli ATCC 25922 and Pseudomonas. aeruginosa ATCC 27853 as quality control organisms.

Clustering antibio-dendrogram by BioNumerics software ver.7.1 (Applied Maths, StMartens-Latem, Belgium) was designed according to ward clustering method. For the slight resemblance between susceptibility profiles of isolates in this study, initially an ambiguous and less efficient antibio-dendrogram was obtained (results not shown). Therefore, to obtain the appropriate sub-clusters with analysable and applicable information, intermediate and resistant interpretive results were assumed equal. Moreover, in order to investigate imipenemresistant strains, results were adjusted based on resistance to imipenem by double insertion of related data.

\section{Genotyping assays}

Primary genetic classification by two multiplex PCR of ompA, csuE and bla OXA-51-like genes without sequencing as latter described in 3LST method(Turton et al., 2007) identified the global most common clonal lineages by three SGs representing ICs.(Zarrilli et al., 2013)

Developed AFLP genomic fingerprinting analysis has previously been described to indicate incidences in incidence infection sources.(Bahador et al, 2013) In which, once double digestion with $\mathrm{MboI}$ and $\mathrm{Mse}$ I enzymes (Fermentas, Lithuania) and ligation by T4 DNA ligase (Takara Bio), PCRs by limited adaptors and primers were conducted (all used adaptors and PCR primers listed in Table S4).

The final data were interpreted using BioNumerics ver.7.1 (Applied Maths, St-MartensLatem, Belgium). Similarity levels of AFLP profiles were calculated by the unweighted pairgroup (UPGMA) method.

\section{Molecular characterization of class D carbapenemases encoding genes and upstream ISs} Prevalence of ISAba/bla $a_{\text {OXA }}$ genes was investigated in studied $A c B$ s to distinguish carbapenems-resistance determinants. The Ambler Class D carbapenemase genes (bla OXA-23, $_{\text {, }}$ 24/40, 51, 58, 143-like genes), ISAbal and ISAba4 elements upstream of the bla $a_{\text {OXA-23-like }}$ gene, and ISAbal upstream of the bla OXA-51-like gene, were detected, which gene sequences with their references were given in Table S4.(Bahador et al, 2015; Higgins et al., 2010a; Woodford et al., 2006)

\section{Statistical analysis}

All statistical analyses were performed by GraphPad Prism 9 (Software, La Jolla, CA). For each of antibiotic-resistance trends, Wilcoxon signed rank test were used to assess significant differences between separate paired nonparametric groups (total, MDR, XDR, CST-R, AGs-R 
strains and increase/decrease magnitudes). Variable importance of genotypic and phenotypic distributions among specimens and locations were displayed by Spearman's signed rank test to compare how each classified groups performed. Fisher exact tests calculated correlation between carbapenems-resistance with ISAba/bla $a_{\text {OXA }}$ genes in groups that estimate their roles on the relevant resistances; likewise, the chi-square test to differentiate the distribution of ISA $b a / b l a_{\mathrm{OXA}}$ genes in various ICs.

\section{Acknowledgements}

We thank all colleagues at Shiraz Namazi Hospital who generously provided strains.

\section{Conflict of interests}

The authors declare no conflict of interest. 
bioRxiv preprint doi: https://doi org/10.1101/2022.03.03.482757; this version posted March 3 , 2022. The copyright holder for this preprint (which was not certified by peer review) is the author/funder, who has granted bioRxiv a license to display the preprint in perpetuity. It is made available under aCC-BY 4.0 International license.

\section{References}

Adams MD, Nickel GC, Bajaksouzian S, Lavender H, Murthy AR, Jacobs MR, Bonomo RA (2009) Resistance to colistin in Acinetobacter baumannii associated with mutations in the PmrAB two-component system. Antimicrob Agents Chemother 53: 3628-3634

Alaei N, Aziemzadeh M, Bahador A (2016) Antimicrobial resistance profiles and genetic elements involved in carbapenem resistance in Acinetobacter baumannii isolates from a referral hospital in Southern Iran. J Glob Antimicrob Resist 5: 75-79

Bahador A, Raoofian R, Pourakbari B, Taheri M, Hashemizadeh Z, Hashemi FB (2015) Genotypic and antimicrobial susceptibility of carbapenem-resistant Acinetobacter baumannii: analysis of ISAba elements and blaOXA-23-like genes including a new variant. Front Microbiol 6: 1249

Bahador A, Taheri M, Pourakbari B, Hashemizadeh Z, Rostami H, Mansoori N, Raoofian R (2013) Emergence of rifampicin, tigecycline, and colistin-resistant Acinetobacter baumannii in Iran; spreading of MDR strains of novel International Clone variants. Microb Drug Resist 19: 397-406

Beceiro A, Moreno A, Fernández N, Vallejo JA, Aranda J, Adler B, Harper M, Boyce JD, Bou G (2014) Biological cost of different mechanisms of colistin resistance and their impact on virulence in Acinetobacter baumannii. Antimicrob Agents Chemother 58: 518-526

Colclough AL, Alav I, Whittle EE, Pugh HL, Darby EM, Legood SW, McNeil HE, Blair JM (2020) RND efflux pumps in Gram-negative bacteria; regulation, structure and role in antibiotic resistance. Future Microbiol 15: 143-157

Coyne S, Courvalin P, Périchon B (2011) Efflux-mediated antibiotic resistance in Acinetobacter spp. Antimicrob Agents Chemother 55: 947-953

Damier-Piolle L, Magnet S, Brémont S, Lambert T, Courvalin P (2008) AdeIJK, a resistancenodulation-cell division pump effluxing multiple antibiotics in Acinetobacter baumannii. Antimicrob Agents Chemother 52: 557-562

De Silva PM, Kumar A (2019) Signal transduction proteins in Acinetobacter baumannii: Role in antibiotic resistance, virulence, and potential as drug targets. Front Microbiol 10: 49

Durante-Mangoni E, Del Franco M, Andini R, Bernardo M, Giannouli M, Zarrilli R (2015) Emergence of colistin resistance without loss of fitness and virulence after prolonged colistin administration in a patient with extensively drug-resistant Acinetobacter baumannii. Diagn Microbiol Infect Dis 82: 222-226

Evans BA, Amyes SG (2014) OXA $\beta$-lactamases. Clin Microbiol Rev 27: 241-263

Fernández-Reyes M, Rodríguez-Falcón M, Chiva C, Pachón J, Andreu D, Rivas L (2009) The cost of resistance to colistin in Acinetobacter baumannii: a proteomic perspective. Proteomics 9: 1632-1645

Fournier PE, Richet H, Weinstein RA (2006) The epidemiology and control of Acinetobacter baumannii in health care facilities. Clin Infect Dis 42: 692-699

Hamouda A, Evans BA, Towner KJ, Amyes SG (2010) Characterization of epidemiologically unrelated Acinetobacter baumannii isolates from four continents by use of multilocus sequence typing, pulsed-field gel electrophoresis, and sequence-based typing of blaOXA-51like genes. J Clin Microbiol 48: 2476-2483

Hancock RE (1984) Alterations in outer membrane permeability. Anпи Rev Microbiol 38: 237-264

Higgins PG, Lehmann M, Seifert H (2010a) Inclusion of OXA-143 primers in a multiplex polymerase chain reaction (PCR) for genes encoding prevalent OXA carbapenemases in Acinetobacter spp. Int J Antimicrob Agents 35: 305

Higgins PG, Lehmann M, Wisplinghoff H, Seifert H (2010b) gyrB multiplex PCR to differentiate between Acinetobacter calcoaceticus and Acinetobacter genomic species 3. $J$ Clin Microbiol 48: 4592-4594 
bioRxiv preprint doi: https//doi.org/10.1101/2022.03.03.482757; this version posted March 3, 2022. The copyright holder for this preprint (which was not certified by peer review) is the author/funder, who has granted bioRxiv a license to display the preprint in perpetuity. It is made available under aCC-BY 4.0 International license.

Humphreys H, Towner K, Crowe M, Webster C, Winter R (1995) Acinetobacter infections, intensive care units, and handwashing. Lancet 345: 121-121

Janssen P, Coopman R, Huys G, Swings J, Bleeker M, Vos P, Zabeau M, Kersters K (1996) Evaluation of the DNA fingerprinting method AFLP as a new tool in bacterial taxonomy. Microbiology 142: 1881-1893

Jenner L, Starosta AL, Terry DS, Mikolajka A, Filonava L, Yusupov M, Blanchard SC, Wilson DN, Yusupova G (2013) Structural basis for potent inhibitory activity of the antibiotic tigecycline during protein synthesis. Proc Natl Acad Sci 110: 3812-3816

Karageorgopoulos DE, Falagas ME (2008) Current control and treatment of multidrugresistant Acinetobacter baumannii infections. Lancet Infect Dis 8: 751-762

Kim B-N, Peleg AY, Lodise TP, Lipman J, Li J, Nation R, Paterson DL (2009) Management of meningitis due to antibiotic-resistant Acinetobacter species. Lancet Infect Dis 9: 245-255

Li J, Nation RL, Owen RJ, Wong S, Spelman D, Franklin C (2007) Antibiograms of multidrug-resistant clinical Acinetobacter baumannii: promising therapeutic options for treatment of infection with colistin-resistant strains. Clin Infect Dis 45: 594-598

Li X-Z, Plésiat P, Nikaido H (2015) The challenge of efflux-mediated antibiotic resistance in Gram-negative bacteria. Clin Microbiol Rev 28: 337-418

Lim LM, Ly N, Anderson D, Yang JC, Macander L, Jarkowski III A, Forrest A, Bulitta JB, Tsuji BT (2010) Resurgence of colistin: a review of resistance, toxicity, pharmacodynamics, and dosing. Pharmacotherapy 30: 1279-1291

Lin M-F, Lin Y-Y, Yeh H-W, Lan C-Y (2014) Role of the BaeSR two-component system in the regulation of Acinetobacter baumannii ade $\mathrm{AB}$ genes and its correlation with tigecycline susceptibility. BMC Microbiol 14: 119

Macfarlane EL, Kwasnicka A, Hancock RE (2000) Role of Pseudomonas aeruginosa PhoPPhoQ in resistance to antimicrobial cationic peptides and aminoglycosides. Microbiology 146: 2543-2554

Magalhães ML, Blanchard JS (2009) Aminoglycosides: mechanisms of action and resistance. In: Antimicrobial drug resistance, pp. 171-181. Springer:

Magiorakos A-P, Srinivasan A, Carey R, Carmeli Y, Falagas M, Giske C, Harbarth S, Hindler J, Kahlmeter G, Olsson-Liljequist B (2012) Multidrug-resistant, extensively drug-resistant and pandrug-resistant bacteria: an international expert proposal for interim standard definitions for acquired resistance. Clin Microbiol Infect 18: 268-281

Magnet S, Blanchard JS (2005) Molecular insights into aminoglycoside action and resistance. Chem Rev 105: 477-498

Mitrophanov AY, Jewett MW, Hadley TJ, Groisman EA (2008) Evolution and dynamics of regulatory architectures controlling polymyxin B resistance in enteric bacteria. PLoS Genet 4: e1000233

Moffatt JH, Harper M, Harrison P, Hale JD, Vinogradov E, Seemann T, Henry R, Crane B, Michael FS, Cox AD (2010) Colistin resistance in Acinetobacter baumannii is mediated by complete loss of lipopolysaccharide production. Antimicrob Agents Chemother 54: 4971-4977 Munoz-Price LS, Weinstein RA (2008) Acinetobacter infection. N Engl J Med 358: 12711281

Nemec A, Maixnerová M, van der Reijden TJ, Van den Broek PJ, Dijkshoorn L (2007) Relationship between the AdeABC efflux system gene content, netilmicin susceptibility and multidrug resistance in a genotypically diverse collection of Acinetobacter baumannii strains. $J$ Antimicrob Chemother 60: 483-489

Olaitan AO, Morand S, Rolain J-M (2014) Mechanisms of polymyxin resistance: acquired and intrinsic resistance in bacteria. Front Microbiol 5: 643

Papp-Wallace KM, Endimiani A, Taracila MA, Bonomo RA (2011) Carbapenems: past, present, and future. Antimicrob Agents Chemother 55: 4943-4960 
bioRxiv preprint doi: https//doi.org/10.1101/2022.03.03.482757; this version posted March 3, 2022. The copyright holder for this preprint (which was not certified by peer review) is the author/funder, who has granted bioRxiv a license to display the preprint in perpetuity. It is made available under aCC-BY 4.0 International license.

Patel JB (2017) Performance standards for antimicrobial susceptibility testing. Clinical and laboratory standards institute

Peleg AY, Hooper DC (2010) Hospital-acquired infections due to gram-negative bacteria. $N$ Engl J Med 362: 1804-1813

Penwell WF, Shapiro AB, Giacobbe RA, Gu R-F, Gao N, Thresher J, McLaughlin RE, Huband MD, DeJonge BL, Ehmann DE (2015) Molecular mechanisms of sulbactam antibacterial activity and resistance determinants in Acinetobacter baumannii. Antimicrob Agents Chemother 59: 1680-1689

Pournaras S, Poulou A, Dafopoulou K, Chabane YN, Kristo I, Makris D, Hardouin J, Cosette P, Tsakris A, Dé E (2014) Growth retardation, reduced invasiveness, and impaired colistinmediated cell death associated with colistin resistance development in Acinetobacter baumannii. Antimicrob Agents Chemother 58: 828-832

Su C-C, Morgan CE, Kambakam S, Rajavel M, Scott H, Huang W, Emerson CC, Taylor DJ, Stewart PL, Bonomo RA (2019) Cryo-electron microscopy structure of an Acinetobacter baumannii multidrug efflux pump. MBio 10: e01295-01219

Tabah A, Koulenti D, Laupland K, Misset B, Valles J, De Carvalho FB, Paiva JA, Çakar N, Ma X, Eggimann P (2012) Characteristics and determinants of outcome of hospital-acquired bloodstream infections in intensive care units: the EUROBACT International Cohort Study. Intensive Care Med 38: 1930-1945

Tacconelli E, Carrara E, Savoldi A, Harbarth S, Mendelson M, Monnet DL, Pulcini C, Kahlmeter G, Kluytmans J, Carmeli Y (2018) Discovery, research, and development of new antibiotics: the WHO priority list of antibiotic-resistant bacteria and tuberculosis. Lancet Infect Dis 18: 318-327

Testing ECoAS, Testing ECoAS (2019) Breakpoint tables for interpretation of MICs and zone diameters. Version 9.0, 2019. EUCAST Available online: http://www eucast org (accessed on 1 January 2020)

Turton J, Gabriel S, Valderrey C, Kaufrnann M, Pitt T (2007) Use of sequence-based typing and multiplex PCR to identify clonal lineages of outbreak strains of Acinetobacter baumannii. Clin Microbiol Infect 13: 807-815

Vaara M (1992) Agents that increase the permeability of the outer membrane. Microbiol Rev 56: 395-411

van de Beek D, Drake JM, Tunkel AR (2010) Nosocomial bacterial meningitis. $N$ Engl J Med 362: 146-154

Vidaillac C, Benichou L, Duval RE (2012) In vitro synergy of colistin combinations against colistin-resistant Acinetobacter baumannii, Pseudomonas aeruginosa, and Klebsiella pneumoniae isolates. Antimicrob Agents Chemother 56: 4856-4861

Vincent J-L, Rello J, Marshall J, Silva E, Anzueto A, Martin CD, Moreno R, Lipman J, Gomersall C, Sakr Y (2009) International study of the prevalence and outcomes of infection in intensive care units. JAMA 302: 2323-2329

Wenzler E, Fraidenburg DR, Scardina T, Danziger LH (2016) Inhaled antibiotics for Gramnegative respiratory infections. Clin Microbiol Rev 29: 581-632

Winfield MD, Groisman EA (2004) Phenotypic differences between Salmonella and Escherichia coli resulting from the disparate regulation of homologous genes. Proc Natl Acad Sci U S A 101: 17162-17167

Woodford N, Ellington MJ, Coelho JM, Turton JF, Ward ME, Brown S, Amyes SG, Livermore DM (2006) Multiplex PCR for genes encoding prevalent OXA carbapenemases in Acinetobacter spp. Int J Antimicrob Agents 27: 351-353

Yahav D, Farbman L, Leibovici L, Paul M (2012) Colistin: new lessons on an old antibiotic. Clin Microbiol Infect 18: 18-29 
bioRxiv preprint doi: https://doi.org/10.1101/2022 03.03 482757; this version posted March 3, 2022. The copyright holder for this preprint (which was not certified by peer review) is the author/funder, who has granted bioRxiv a license to display the preprint in perpetuity. It is made available under aCC-BY 4.0 International license.

Yoon E-J, Chabane YN, Goussard S, Snesrud E, Courvalin P, Dé E, Grillot-Courvalin C (2015) Contribution of resistance-nodulation-cell division efflux systems to antibiotic resistance and biofilm formation in Acinetobacter baumannii. MBio 6

Yoon E-J, Courvalin P, Grillot-Courvalin C (2013) RND-type efflux pumps in multidrugresistant clinical isolates of Acinetobacter baumannii: major role for AdeABC overexpression and AdeRS mutations. Antimicrob Agents Chemother 57: 2989-2995

Zarrilli R, Pournaras S, Giannouli M, Tsakris A (2013) Global evolution of multidrugresistant Acinetobacter baumannii clonal lineages. Int J Antimicrob Agents 41: 11-19 
bioRxiv preprint doi: https//doi.org/10.1101/2022.03.03.482757; this version posted March 3, 2022. The copyright holder for this preprint

\section{Figure legends}

Figure 1. Investigation of trends in antibiotic resistance in target groups, antibiotics profiles differentiation between abnormalities.

A Antibio-dendrogram, antimicrobial classification showing 16 antibiotypes defined with $71 \%$ similarity cut-off; antimicrobial phenotypes named based on Latin numbers; antimicrobial susceptibility patterns of 20 antibiotics; imipenem MICs $(\mu \mathrm{g} / \mathrm{mL})$ to compare with disk diffusion results; resistance phenotypes to determine resistance levels; AFLP genotypes to compare with antibiotic phenotypes; PCR results of genes ISAba/bla $a_{\text {OXA }}$, respectively. Dark, light and white colours boxes denote resistance, intermediate and sensitive requests in Etest assays.

Comparing the trends of antibiotic resistance percentages in total studied $A c B$ strains with:

B MDR and XDR.

C CST-R and AGs-R.

D Abnormalities in heatmap based on normalized values.

E Differentiation between abnormalities distributions displayed in Box and ribbon plots and

F Heatmap depicting statistical significance in antibiotic resistant groups.

$\mathrm{G}$ Decrease and increase of antimicrobial resistances in CST-R than total strains and

H AGs-R than MDR strains.

$P$ values and significance levels were determined by Wilcoxon matched-pairs signed rank test, and ns denotes not significant.

Abbreviations: AGs, aminoglycosides; AMC, amoxicillin-clavulanate; CIP, ciprofloxacin; CST, colistin (polymyxin E); CTX, cefotaxime; CTX/CA, cefotaxime- clavulanate; DXC, doxycycline; FEP, cefepime; IPM, imipenem; ISs, insertion sequences; KAN, kanamycin; LVX, levofloxacin; MDR multi drug-resistant; MEM, meropenem; MIN, minocycline; NET, netilmicin; PDR, pan drug-resistance; PIP, piperacillin; SAM, ampicillin-sulbactam; SXT, trimethoprim-sulfamethoxazole; TGC, tigecycline; TIM, ticarcillin-clavulanate; TOB, tobramycin; TZP, piperacillin-tazobactam; XDR, extensively drug-resistance.

\section{Figure 2. Genetic, resistance and epidemiological factors involved in $A c B$ expansion.}

A Outline of abnormal AGs-R, CST-R strains; genotypic classifications of AFLPdendrogram; clinical data to detailed transformations with respect to spatial and sample distributions; worldwide clonal lineages, another genotypes used for design AFLPdendrogram; PCR assay of ISAba/bla $a_{\mathrm{OXA}}$ genes displaying role of resistance in strains distribution. Constructed AFLP-dendrogram using two cut-off levels at $78 \%$ and $90 \%$ similarity and Dice coefficient with parameter settings at one \% optimization and one \% tolerance limit, displayed 25 genotypes. Repeated cases are shown in boldface type and markers represent: (A), abnormal NET-R strains; (C), abnormal CST-R strains; 2 , IC2/SG1; (1) IC1/SG2; $\bullet$, SG variants; corresponding to the international clones (ICs) II and I. B Heatmap displaying significant relationships using Fisher exact tests between ISAba/bla $a_{\text {OXA }}$ genes and carbapenems resistances.

$\mathrm{C}$ Present of ISAba/bla $\mathrm{OXX}_{\mathrm{A}}$ genes in various global outbreaks, normalized to compare categories.

D-F Comparison of genotypic and phenotypic distribution of studied $A c B$ isolates in different specimens, and

G-I ICUs. International clones of IC1 and IC2 represent SG1 and SG2, respectively, also SGv: SG variant. XDR and PDR strains indicate mot resistant samples. The Spearman's correlation coefficients show similar distributions of infectious samples in different ICs and most resistant strains than total with respect to infectious (D and E) and spatial samples (G 
and $\mathrm{H}$ ). Maximum values of worldwide clones and resistant strains were showed in $\mathrm{F}$ and $\mathrm{I}$ by input normalized data,

$\mathrm{J}$ then maximum number (100) were assay to found statistical trends in this situations by Fisher exact tests.

Abbreviations: B, blood; C, cerebrospinal fluid; Cen, central ICU; E, eye secretion; ICU, intensive care unit; Int, internal ICU; ISs, insertion sequences; MDR multi drug-resistant; N, nose secretion; Neo, neonatal ICU; Neu, neurosurgical ICU; PDR, pan drug-resistance; Ped, pediatric ICU; S, sputum; SG, sequence groups; Sur, surgical ICU; Tra, transplant ICU; U, urine; W, wound; XDR, extensively drug-resistance.

\section{Figure 3. The synchronic resisto-genesis effects phenomenon identified in this study.}

Once detected hyper-susceptible Acinetobacter baumannii strains resistance to colistin and aminoglycosides in this study, the abnormal antibiogram results found then matched with the previously studies; consequently, the synchronic resisto-genesis effects phenomenon was introduced. In which nonspecific predominant mechanisms by moderate to mild simultaneous changes on drug-resistances (greatly here on colistin and aminoglycosides) create abnormalities, and significantly lead Acinetobacter populations as the deadliest nosocomial infections in critical ICU patients to made unpredictable experimental treatment. Two abnormalities were:

Left. In colistin-resistant strains, LPS loss in outer-membrane induce colistin-resistance that increase sensitivity and penetration to all drugs, except tetracyclines and tigecycline.

Right. In aminoglycoside-resistant strains, upregulated genes related to AdeABC pumps increase corresponding substrates extrude and resistance to the most antibiotics, especially aminoglycosides.

Therefore, this method interestingly has beneficial effects on predicting combination therapy based on preclinical results.

\section{SUPPORTING INFORMATION}

Table S1. Applied antibiotics trends in different antibiotics levels and classes, calculated physicochemical properties of antibiotics.

Table S2. Distribution of resistance percentages of bla $a_{\mathrm{OxA}}$ and IS genes in different international clones.

Table S3. Summary of the target genes and adaptors sequences utilized in this study. 


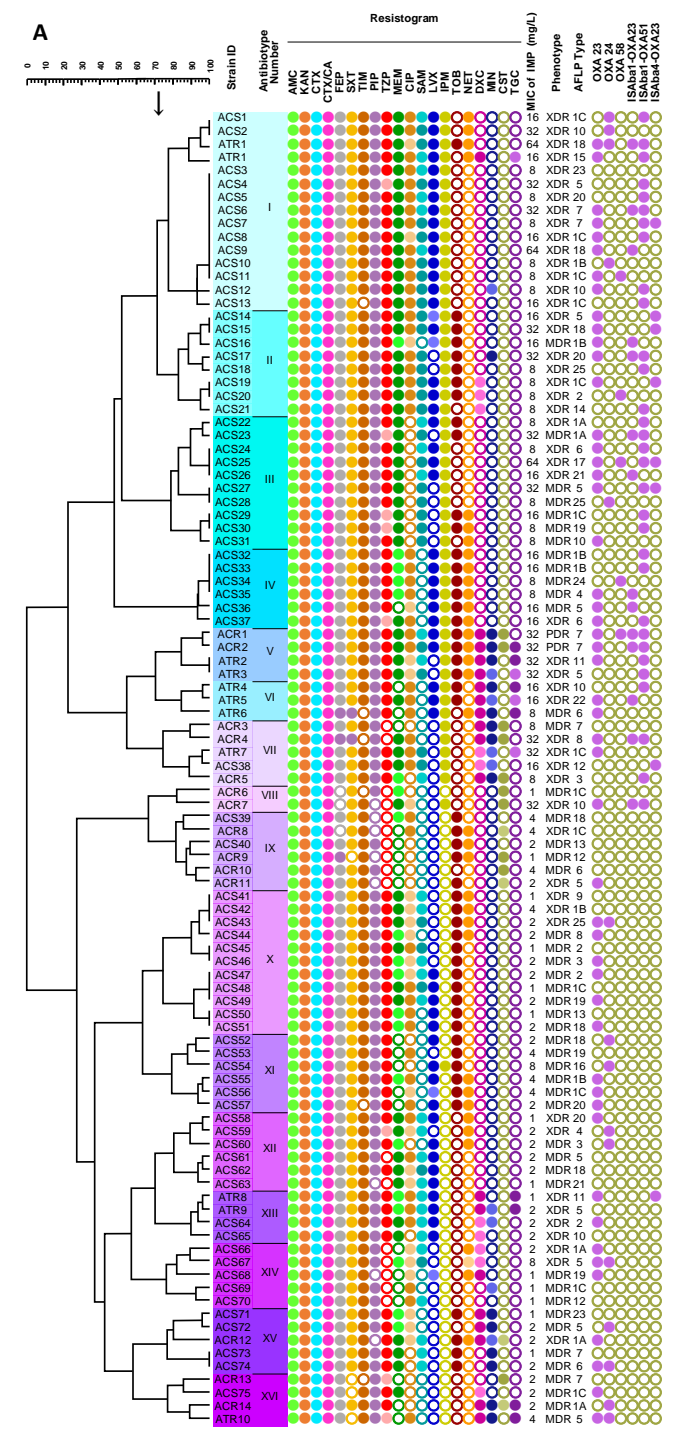

B
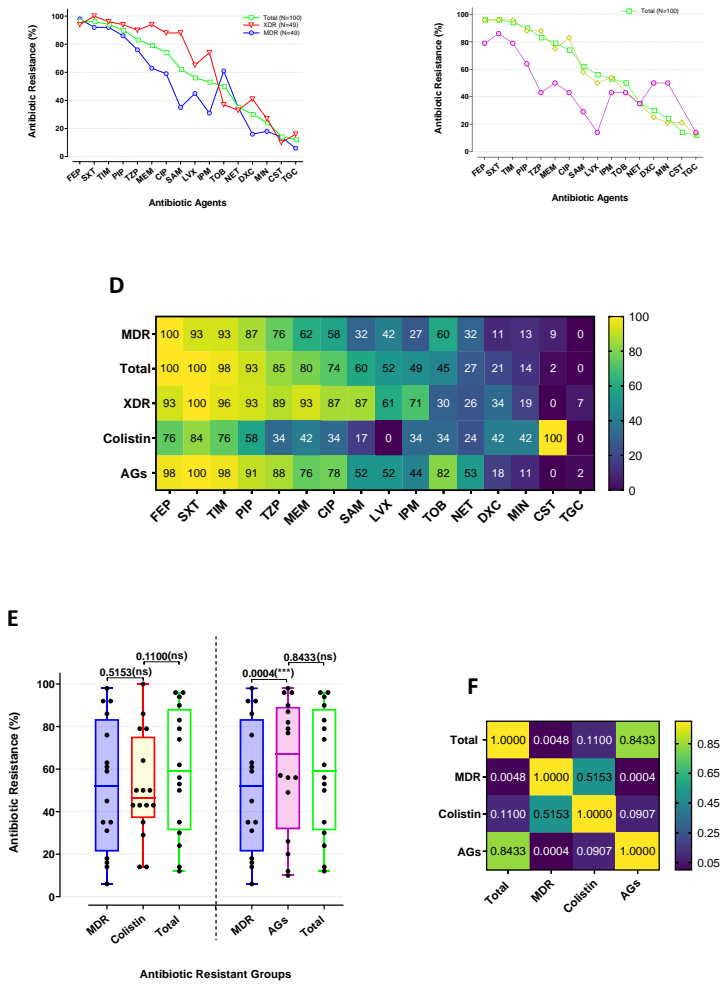

G

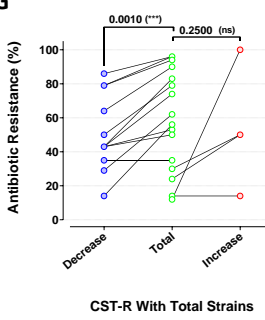

C

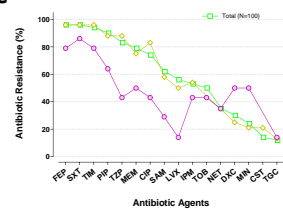

Figure 1. Investigation of trends in antibiotic resistance in target groups, antibiotics profiles differentiation between abnormalities

(A) Antibio-dendrogram, antimicrobial classification showing 16 antibiotypes defined with $71 \%$ similarity cutoff; antimicrobial phenotypes named based on Latin numbers; antimicrobial susceptibility patterns of 20 antibiotics; imipenem MICs $(\mu \mathrm{g} / \mathrm{mL})$ to compare with disk diffusion results; resistance phenotypes to determine resistance levels; AFLP genotypes to compare with antibiotic phenotypes; PCR results of genes ISAba/bla $a_{\mathrm{OXA}}$, respectively. Dark, light and white colours boxes denote resistance, intermediate and sensitive requests in Etest assays.

Comparing the trends of antibiotic resistance percentages in total studied $A c B$ strains with:

(B) MDR and XDR.

(C) CST-R and AGs-R.

(D) Abnormalities in heatmap based on normalized values.

(E) Differentiation between abnormalities distributions displayed in Box and ribbon plots and

(F) Heatmap depicting statistical significance in antibiotic resistant groups.

(G) Decrease and increase of antimicrobial resistances in CST-R than total strains and

(H) AGs-R than MDR strains.

$P$ values and significance levels were determined by Wilcoxon matched-pairs signed rank test, and ns denotes not significant.

Abbreviations: AGs, aminoglycosides; AMC, amoxicillin-clavulanate; CIP, ciprofloxacin; CST, colistin (polymyxin E); CTX, cefotaxime; CTX/CA, cefotaxime- clavulanate; DXC, doxycycline; FEP, cefepime; IPM, imipenem; ISs, insertion sequences; KAN, kanamycin; LVX, levofloxacin; MDR multi drug-resistant; MEM, meropenem; MIN, minocycline; NET, netilmicin; PDR, pan drug-resistance; PIP, piperacillin; SAM, ampicillinsulbactam; SXT, trimethoprim-sulfamethoxazole; TGC, tigecycline; TIM, ticarcillin-clavulanate; TOB, tobramycin; TZP, piperacillin-tazobactam; XDR, extensively drug-resistance. 
A

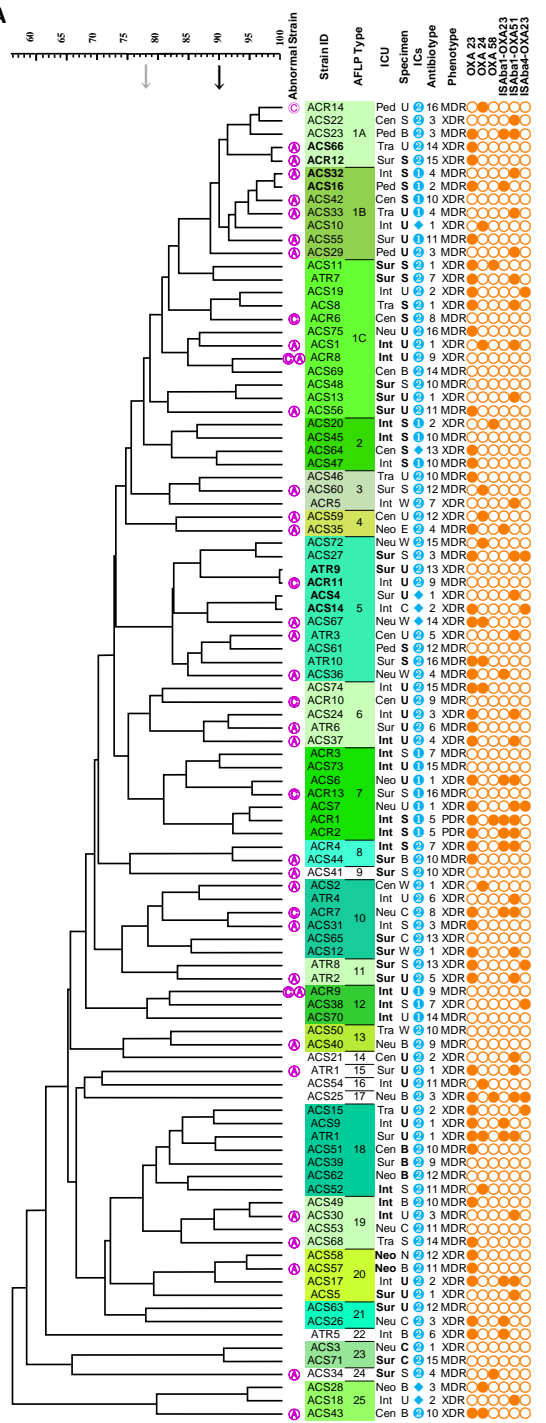

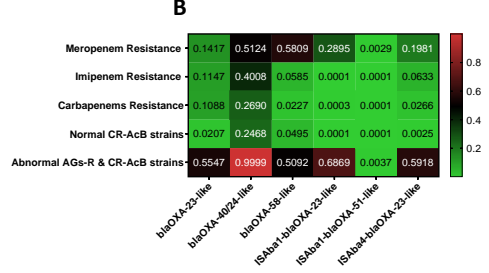

D

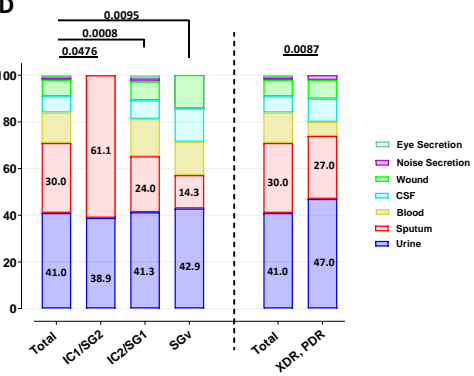

G
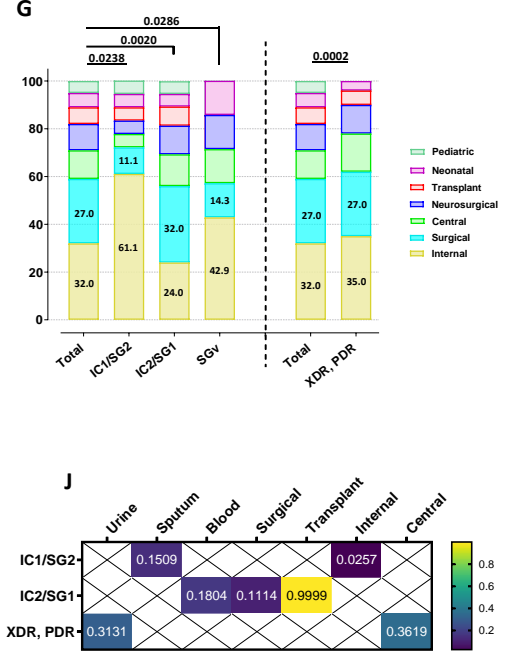

C

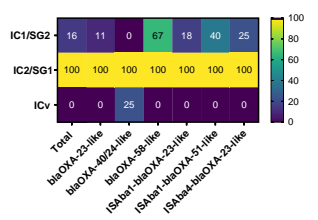

E
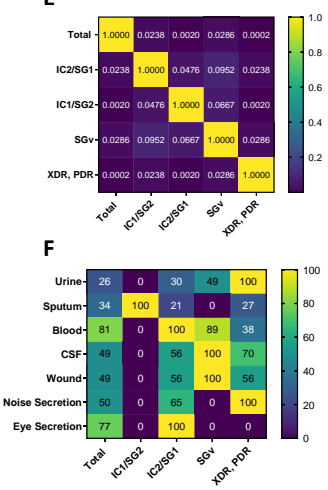

H
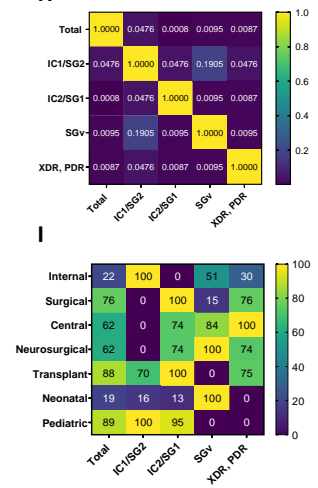

Figure 2. Genetic, resistance and epidemiological factors involved in $A c B$ expansion.

(A) Outline of abnormal AGs-R, CST-R strains; genotypic classifications of AFLP-dendrogram; clinical data to detailed transformations with respect to spatial and sample distributions; worldwide clonal lineages, another genotypes used for design AFLP-dendrogram; PCR assay of ISAba/bla $a_{\mathrm{OXA}}$ genes displaying role of resistance in strains distribution. Constructed AFLP-dendrogram using two cut-off levels at $78 \%$ and $90 \%$ similarity and Dice coefficient with parameter settings at one \% optimization and one \% tolerance limit, displayed 25 genotypes. Repeated cases are shown in boldface type and markers represent: (A), abnormal NET-R strains; (C), abnormal CST-R strains; 2, IC2/SG1; 1, IC1/SG2;, SG variants; corresponding to the international clones (ICs) II and I.

(B) Heatmap displaying significant relationships using Fisher exact tests between ISAba/bla $a_{\text {OXA }}$ genes and carbapenems resistances.

(C) Present of ISA $b a / b l a_{\mathrm{OXA}}$ genes in various global outbreaks, normalized to compare categories.

(D-F) Comparison of genotypic and phenotypic distribution of studied $A c B$ isolates in different specimens, and

(G-I) ICUs. International clones of IC1 and IC2 represent SG1 and SG2, respectively, also SGv: SG variant. XDR and PDR strains indicate mot resistant samples. The Spearman's correlation coefficients show similar distributions of infectious samples in different ICs and most resistant strains than total with respect to infectious (D and E) and spatial samples ( $\mathrm{G}$ and $\mathrm{H})$. Maximum values of worldwide clones and resistant strains were showed in $\mathrm{F}$ and $\mathrm{I}$ by input normalized data,

(J) then maximum number (100) were assay to found statistical trends in this situations by Fisher exact tests.

Abbreviations: B, blood; C, cerebrospinal fluid; Cen, central ICU; E, eye secretion; ICU, intensive care unit; Int, internal ICU; ISs, insertion sequences; MDR multi drug-resistant; N, nose secretion; Neo, neonatal ICU; Neu, neurosurgical ICU; PDR, pan drug-resistance; Ped, pediatric ICU; S, sputum; SG, sequence groups; Sur, surgical ICU; Tra, transplant ICU; U, urine; W, wound; XDR, extensively drug-resistance. 


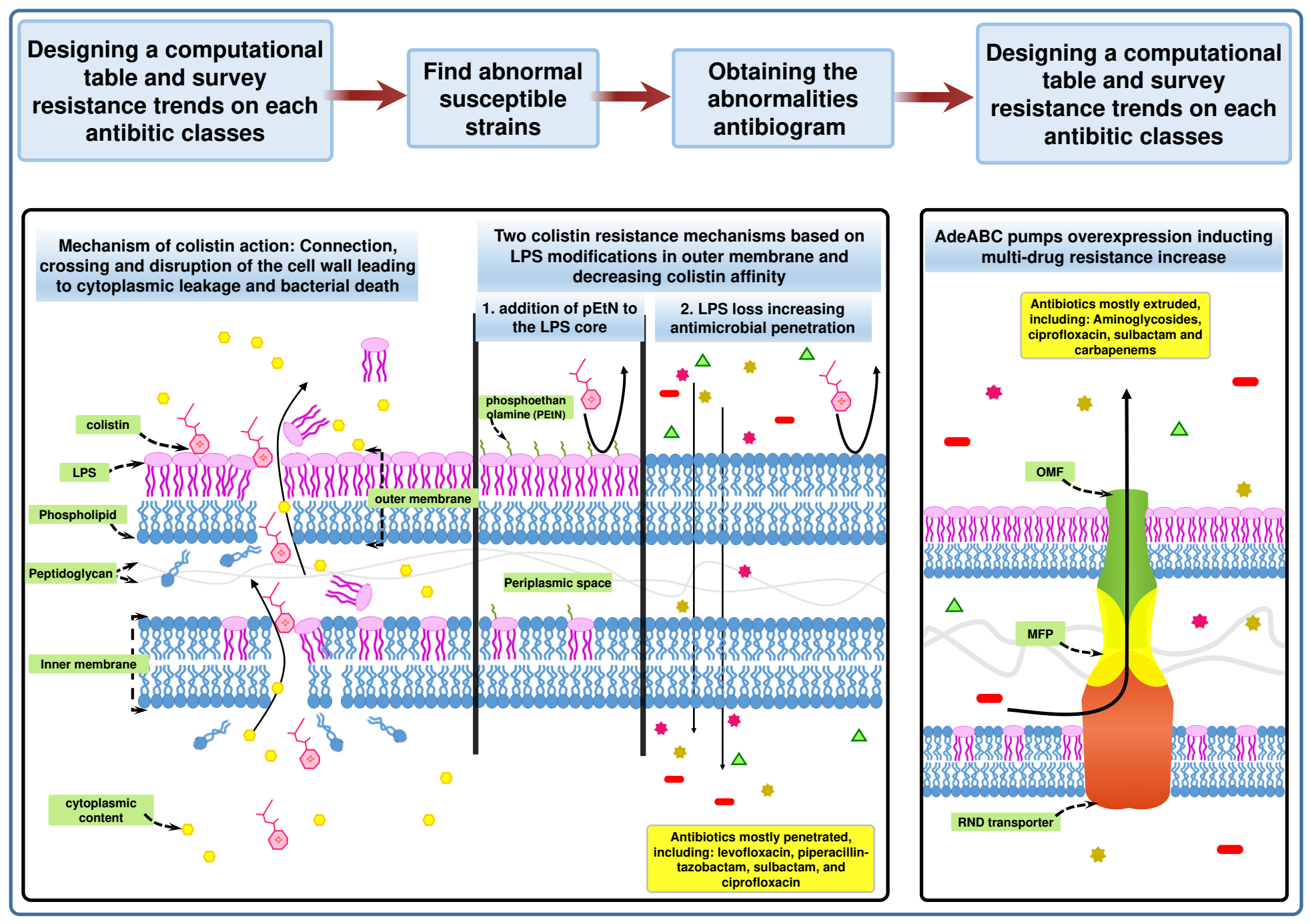

Fig. 3. The synchronic resisto-genesis effects phenomenon identified in this study.

Once detected hyper-susceptible Acinetobacter baumannii strains resistance to colistin and aminoglycosides in this study, the abnormal antibiogram results found then matched with the previously studies; consequently, the synchronic resisto-genesis effects phenomenon was introduced. In which nonspecific predominant mechanisms by moderate to mild simultaneous changes on drug-resistances (greatly here on colistin and aminoglycosides) create abnormalities, and significantly lead Acinetobacter populations as the deadliest nosocomial infections in critical ICU patients to made unpredictable experimental treatment. Two abnormalities were:

Left. In colistin-resistant strains, LPS loss in outer-membrane induce colistin-resistance that increase sensitivity and penetration to all drugs, except tetracyclines and tigecycline.

Right. In aminoglycoside-resistant strains, upregulated genes related to AdeABC pumps increase corresponding substrates extrude and resistance to the most antibiotics, especially aminoglycosides.

Therefore, this method interestingly has beneficial effects on predicting combination therapy based on preclinical results. 